\title{
Plaque Formation Assay for Human Parainfluenza Virus Type 1
}

\author{
Keijo Fukushima, ${ }^{a}$ Tadanobu Takahashi, ${ }^{a}$ Masahiro Takaguchi, ${ }^{a}$ Hiroo Ueyama, ${ }^{a}$ Seigo Ito, ${ }^{a}$ \\ Yuuki Kurebayashi, ${ }^{a}$ Tomohiro Kawanishi, ${ }^{a}$ Jennifer Lois McKimm-BreschKin, ${ }^{b}$ Toru Takimoto, ${ }^{c}$ \\ Akira Minami, ${ }^{a}$ and Takashi SuzUKI ${ }^{*, a}$ \\ ${ }^{a}$ Department of Biochemistry, School of Pharmaceutical Sciences and Global COE Program for Innovation in Human \\ Health Sciences, University of Shizuoka; 52-1 Yada, Shizuoka 422-8526, Japan: ${ }^{b}$ CSIRO Molecular and Health \\ Technologies; 343 Royal Parade, Parkville 3052, Australia: and ${ }^{c}$ Department of Microbiology and Immunology, University \\ of Rochester Medical Center; 601 Elmwood Ave., Box 672, Rochester, NY 14642, U.S.A.
}

Received December 3, 2010; accepted March 28, 2011

Human parainfluenza virus type 1 (hPIV1) generally does not show visible plaques in common cell lines, including Lewis lung carcinoma-monkey kidney (LLC-MK $\mathbf{K}_{2}$ ) cells, by plaque formation assays for human parainfluenza virus type 3 (hPIV3) and Sendai virus. In several conditions of the plaque formation assay, complete elimination of serum proteins in the overlay medium was necessary for visualization of hPIV1-induced plaque formation in LLC-MK cells. We developed a plaque formation assay for hPIV1 isolation and titration in LLC$\mathrm{MK}_{2}$ cells using an initial overlay medium of bovine serum albumin-free Eagle's minimum essential medium containing agarose and acetylated trypsin for $4-6 \mathrm{~d}$ followed by a second overlay staining medium containing agarose and neutral red. The assay allowed both laboratory and clinical hPIV1 strains to form large plaques. The plaque reduction assay was also performed with rabbit anti-hPIV1 antibody as a general evaluation model of viral inhibitors to decrease both the plaque number and size. The results indicate that the plaque formation assay is useful for hPIV1 isolation, titration, evaluation of antiviral reagents and epidemiologic research.

Key words human parainfluenza virus type 1; plaque assay; isolation; Lewis lung carcinoma-monkey kidney cell; antiviral reagent

Human parainfluenza virus type 1 (hPIV1; genus Respirovirus, subfamily Paramyxovirinae, family Paramyxoviridae, order Mononegavirales) possesses a hemagglutininneuraminidase $(\mathrm{HN})$ glycoprotein and a fusion glycoprotein on the viral envelope. After trypsin-like proteases cleave the fusion glycoprotein into a large F1 subunit and a small F2 subunit, the virus can fuse with the cell membrane and invade cells. hPIV1 often causes severe respiratory tract illness that can lead to hospitalization of infants and young children $^{1,2)}$ and occasionally causes sudden death of newborns and infants. ${ }^{3)}$ Since there is no clinical therapy for or vaccine against hPIV1, an effective strategy for prevention of hPIV1 infection, especially in developed countries with a low birthrate, is needed. For development of hPIV1 vaccines and antiviral reagents, basic techniques for virus isolation such as a plaque assay are necessary. An immunofluorescent antibody assay, ${ }^{4)}$ the hemadsorption assay ${ }^{4}$ and reverse transcription real-time polymerase chain reactions $(\mathrm{PCR})^{5}$ ) have generally been used for hPIV1 isolation and detection. These methods are useful for accurate and sensitive detection of hPIV1, but not effective to isolate the virus. On the other hand, the plaque assay can be used to purify a clonal population of virus or to determine viral titer as plaque-forming units. Additionally, the assay could be applied to estimate antiviral reagents or select mutant strains because a plaque size reflects virus propagations.

Human parainfluenza virus type 3 (hPIV3; genus Respirovirus, subfamily Paramyxovirinae, family Paramyxoviridae, order Mononegavirales) has been reported to form large plaques in human epidermoid cancer (HEp-2) cells in Dulbecco's modified Eagle's medium (DMEM) with $0.3 \%$ agarose. ${ }^{6}$ Sendai virus (SeV; genus Respirovirus, subfamily Paramyxovirinae, family Paramyxoviridae, order Mononegavirales) has been reported to form large plaques in several cell lines with neutral red staining, ${ }^{7-9)}$ and recombinant $\mathrm{SeV}$ possessing HN genes from hPIV1 or hPIV3 has also been reported to form plaques in Lewis lung carcinoma-monkey kidney $\left(\right.$ LLC-MK $\left.{ }_{2}\right)$ cells in Eagle's minimum essential medium (MEM) with $2 \%$ bovine serum albumin (BSA) or $5 \%$ fetal bovine serum (FBS) ${ }^{10-12)}$ In contrast, no clear plaque formation of hPIV1 was observed by these methods reported for hPIV3 or recombinant $\mathrm{SeV}$ possessing hPIV1 HN glycoprotein. Plaque formation of hPIV1 has been difficult to visualize because the virus does not show obvious cytotoxicity and syncytium formation activity, in comparison with that of hPIV3 and $\mathrm{SeV}^{13,14)}$ It is necessary to select and optimize appropriate media and cell lines in order to realize visible plaque formation of hPIV1.

From tests of 4 cell lines, 3 kinds of medium and different concentrations of additives and cell culture times, we developed a visible-plaque formation assay for hPIV1 by using an overlay medium (MEM containing $0.8 \%$ agarose and $3 \mu \mathrm{g} / \mathrm{ml}$ acetylated trypsin without FBS and BSA) and an overlay staining medium (MEM containing $0.8 \%$ agarose and $0.25 \mathrm{mg} / \mathrm{ml}$ neutral red) for hPIV1 isolation and titration in LLC-MK ${ }_{2}$ cells. We found that serum proteins such as BSA strongly inhibited visualization of hPIV1-induced plaques. The assay allowed both laboratory and clinical hPIV1 strains to form large plaques without cell fixation enabling isolation of the live virus clones. The plaque assay could also be applied to a plaque reduction assay, which has been widely used to evaluate efficiency or resistance for antiviral reagents. ${ }^{15,16)}$ Establishment of the hPIV1 plaque assay will accelerate basic research on the virus, especially phylogenic study from clinical isolates and selection of drug candidates against hPIV1. 


\section{MATERIALS AND METHODS}

Cells, Viruses and Antibodies LLC-MK 2 cells were maintained in MEM supplemented with 5\% heat-inactivated FBS. The hPIV1 strain C35, the hPIV3 strain C243 and the hPIV1 clinical isolate CL-5 were kindly provided by Allen Portner (St. Jude Children's Research Hospital). C35 and C243 were propagated in LLC-MK 2 cells. CL-5, which was utilized as clinical strain, ${ }^{17}$ was isolated in 1973 from infected children ${ }^{18)}$ and passaged totally seven times in LLC$\mathrm{MK}_{2}$ cells after isolation. The $\mathrm{SeV}$ strain Enders was propagated in 10-d-old embryonated hen's eggs for $2 \mathrm{~d}$ at $34^{\circ} \mathrm{C}$. Rabbit anti-hPIV1 antibody was prepared by immunization with $\mathrm{C} 35$ as described previously ${ }^{19)}$ and purified on a Protein G column HiTrapTM Protein G HP (CE Healthcare Biosciences Corp., Priscataway, NJ, U.S.A.).

Plaque Formation Assay $\mathrm{LLC}-\mathrm{MK}_{2}$ cells were grown to complete confluence with MEM containing 5\% FBS in a 6-well tissue culture plate (FALCON, Franklin Lakes, NJ, U.S.A.) at $37^{\circ} \mathrm{C}$ under $5 \% \mathrm{CO}_{2}$. The growth medium was removed and the cell monolayers were washed once with phosphate-buffered saline (PBS; pH 7.2, $131 \mathrm{~mm} \mathrm{NaCl}$, $14 \mathrm{mM} \mathrm{Na}_{2} \mathrm{HPO}_{4}, 1.5 \mathrm{~mm} \mathrm{KH} \mathrm{PO}_{4}$ and $2.7 \mathrm{~mm} \mathrm{KCl}$ ). Ten-fold serial dilutions of hPIV1 C35 or CL-5 in a serum-free medium, SFM (Hybridoma-SFM; Invitrogen Corp., Carlsbad, CA, U.S.A.), were inoculated and incubated for $30 \mathrm{~min}$ at room temperature. During the virus adsorption, the overlay medium was prepared as follows: $2 \times$ concentrated MEM containing $6 \mu \mathrm{g} / \mathrm{ml}$ acetylated trypsin was warmed to $37^{\circ} \mathrm{C}$ in a water bath, and 1.6\% agarose (Bacto Agar; Becton, Dickinson and Co., Franklin Lakes, NJ, U.S.A.) in ultrapure water was melted at $92^{\circ} \mathrm{C}$ for $15 \mathrm{~min}$ and then kept at $60^{\circ} \mathrm{C}$. The $2 \times$ concentrated MEM was mixed with the agarose to prepare the overlay medium $(1 \times \mathrm{MEM}, 0.8 \%$ agarose and $3 \mu \mathrm{g} / \mathrm{ml}$ acetylated trypsin). After removing the virus inoculum, the cell monolayers were washed once with PBS. Four milliliters of the overlay medium was added to each well. After the overlay medium had set, the plate was incubated in an upside-down position for 4 or $6 \mathrm{~d}$ (for hPIV1 strain C35, $4 \mathrm{~d}$; for hPIV1 isolate CL-5, $6 \mathrm{~d}$ ) at $37^{\circ} \mathrm{C}$ under $5 \% \mathrm{CO}_{2}$. The overlay staining medium was prepared as follows: $2 \times$ concentrated MEM containing $0.5 \mathrm{mg} / \mathrm{ml}$ neutral red (Polysciences, Inc., Warrington, PA, U.S.A.) was warmed to $37^{\circ} \mathrm{C}$ in a water bath and $1.6 \%$ agarose in ultrapure water was melted at $92{ }^{\circ} \mathrm{C}$ for $15 \mathrm{~min}$ and then kept at $60^{\circ} \mathrm{C}$. The $2 \times$ concentrated MEM was mixed with the agarose to prepare the overlay staining medium $(1 \times$ MEM, $0.8 \%$ agarose and $0.25 \mathrm{mg} / \mathrm{ml}$ neutral red). On days $4-6,2 \mathrm{ml}$ of the overlay staining medium was added to the overlay medium of each well. After the overlay staining medium had set, the plate was again incubated in an upside-down position for an additional $3 \mathrm{~d}$ at $37^{\circ} \mathrm{C}$ under $5 \% \mathrm{CO}_{2}$. When plaques were not clear, the plate was left for an additional $1 \mathrm{~d}$ or $2 \mathrm{~d}$. For a total of $6-10 \mathrm{~d}$, the plaques were visualized as white circles.

The assay was tested by selection of several media for LLC-MK $\mathrm{MK}_{2}$ cells or HEp-2 cells. Overlay medium consisting of $1 \times$ MEM, DMEM or SFM, $0.8 \%$ agarose, 3 or $5 \mu \mathrm{g} / \mathrm{ml}$ acetylated trypsin without or with $2 \% \mathrm{BSA}$ and without or with $5 \%$ FBS and overlay staining medium consisting of $1 \times$ MEM, DMEM or SFM, $0.8 \%$ agarose, $0.25,0.16$ or $0.08 \mathrm{mg} / \mathrm{ml}$ neutral red without or with $5 \%$ FBS were used for hPIV1 and SeV plaque formation assay in LLC-MK cells. Overlay medium consisting of $1 \times$ DMEM, $0.8 \%$ agarose and $3 \mu \mathrm{g} / \mathrm{ml}$ acetylated trypsin and overlay staining medium consisting of $1 \times$ DMEM, $0.8 \%$ agarose and $0.25 \mathrm{mg} / \mathrm{ml}$ neutral red were used for hPIV1 and hPIV3 plaque formation assay in HEp-2 cells.

Immunological Detection of Virus-Infected Cells After plaque formation, the cell monolayers in a well were fixed with $3 \mathrm{ml}$ of ethanol-acetic acid mixture $(5: 1)$ for $2 \mathrm{~d}$ at $4{ }^{\circ} \mathrm{C}$. The overlay media were removed carefully and the cell monolayers were washed twice with PBS. hPIV1infected cells were detected by probing with a rabbit antihPIV1 antibody diluted $1: 200$ with PBS at room temperature for $30 \mathrm{~min}$, followed by horseradish peroxidase (HRP)conjugated Protein A (Sigma-Aldrich, St. Louis, MO, U.S.A.) at room temperature for $30 \mathrm{~min}$ as described previously. ${ }^{19)}$ Each step was preceded by washing wells three times with PBS. Finally, the virus-infected cells were stained by addition of an immunostaining reagent containing $\mathrm{H}_{2} \mathrm{O}_{2}$, $N, N$-diethyl- $p$-phenylenediamine sulfate and 4-chloro-1naphthol in $100 \mathrm{~mm}$ citrate buffer ( $\mathrm{pH} \mathrm{6.0)}$ ) as described previously. ${ }^{20,21)}$ The cells were washed with deionized water and dried.

Plaque Reduction Assay To examine inhibition of virus growth, rabbit anti-hPIV1 antibody dilutions $(1: 100,1: 200$ or $1: 400)$ as an inhibitor were mixed with the overlay medium. As a control for complete inhibition of hPIV1 growth, the overlay medium without acetylated trypsin was used. The overlay staining medium was the same as that described for the plaque formation assay.

\section{RESULTS}

Plaque Formation Assay for the hPIV1 Laboratory Strain C35 and the Clinical Isolate CL-5 Several parameters including cell lines, types of overlay medium, staining reagents, various brands of agarose and carboxy methyl cellulose, and culture conditions were tested to establish a plaque assay for hPIV1 isolation. Plaque assay conditions we tried for the establishment were summarized in Table 1. As a result, we found that hPIV1 produced large plaques in LLC$\mathrm{MK}_{2}$ cells, which were detected by the addition of a second overlay staining medium $(1 \times$ MEM, $0.8 \%$ agarose and $0.25 \mathrm{mg} / \mathrm{ml}$ neutral red) after incubation with the initial overlay medium $(1 \times$ MEM, $0.8 \%$ agarose and $3 \mu \mathrm{g} / \mathrm{ml}$ acetylated trypsin) for $4 \mathrm{~d}$ without cell fixation. On day 4 after virus infection, plaques were barely visible. After staining with neutral red for an additional $3 \mathrm{~d}$, plaques were clearly visualized as white circles in a virus dilution-dependent manner (Fig. 1A). By immunological detection of the virus-infected cells after fixing with an ethanol-acetic acid mixture $(5: 1)$ for $2 \mathrm{~d}$ at $4{ }^{\circ} \mathrm{C}$, all plaques were clearly stained dark-gray as foci. Some foci that were not visible in a plaque assay with neutral red were also detected as small foci (Fig. 1B). Plaques of the clinical isolate CL-5 were also visualized similar to the laboratory strain C35 (Fig. 1C). Therefore, the assay was also useful for detection and isolation of the hPIV1 clinical strain as well as the laboratory strain.

Additionally, we demonstrated that hPIV3 also formed visible plaques in LLC-MK $\mathrm{MK}_{2}$ cells under the same conditions as those for the hPIV1 virus. We also tried to isolate respective 
viruses from the mixture of hPIV1 strain C35 and hPIV3 strain C243, and hPIV1 and hPIV3 could be separated from each other by picking individual plaques (data not shown). This result confirmed that the assay is useful for isolation of

Table 1. Summary of hPIV1 Plaque Assay Parameters and Results

\begin{tabular}{|c|c|c|c|c|}
\hline Cell & Medium & Additive & Day & Result \\
\hline HEp-2 & DMEM & $0.5 \mathrm{mg} / \mathrm{ml}$ neutral red* & 7 & - \\
\hline MDCK & MEM & $0.5 \mathrm{mg} / \mathrm{ml}$ neutral red* & 7 & - \\
\hline HeLa & DMEM & $0.5 \mathrm{mg} / \mathrm{ml}$ neutral red* & 7 & - \\
\hline HEp-2 & DMEM & & $15<$ & - \\
\hline LLC-MK ${ }_{2}$ & SFM & & $15<$ & - \\
\hline LLC-MK ${ }_{2}$ & MEM & & $15<$ & + \\
\hline LLC-MK ${ }_{2}$ & MEM & $0.25 \mathrm{mg} / \mathrm{ml} \mathrm{neutral} \mathrm{red}$ & $7-9$ & ++ \\
\hline LLC-MK ${ }_{2}$ & MEM & $\begin{array}{l}0.08 \mathrm{mg} / \mathrm{ml} \text { neutral red, } \\
2 \% \mathrm{BSA}\end{array}$ & $9<$ & - \\
\hline LLC-MK ${ }_{2}$ & MEM & $\begin{array}{l}0.08 \mathrm{mg} / \mathrm{ml} \text { neutral red, } \\
5 \% \mathrm{FBS}\end{array}$ & $9<$ & - \\
\hline LLC-MK ${ }_{2}$ & MEM & $0.08 \mathrm{mg} / \mathrm{ml}$ neutral red & $9<$ & + \\
\hline LLC-MK ${ }_{2}$ & MEM & $\begin{array}{l}0.25 \mathrm{mg} / \mathrm{ml} \text { neutral red, } \\
2 \% \mathrm{BSA}\end{array}$ & $9<$ & + \\
\hline LLC-MK ${ }_{2}$ & DMEM & $0.25 \mathrm{mg} / \mathrm{ml}$ neutral red & $9<$ & + \\
\hline LLC-MK ${ }_{2}^{2}$ & SFM & $0.25 \mathrm{mg} / \mathrm{ml}$ neutral red & $9<$ & + \\
\hline HEp-2 & DMEM & $0.25 \mathrm{mg} / \mathrm{ml}$ neutral red & $9<$ & - \\
\hline
\end{tabular}

-, No plaques were observed. + , Few plaques were observed but they were too small and unclear. ++ , Clear and large plaques were observed. * Neutral red was added as an aqueous solution after fixing the cells. the hPIV1 strain.

Selection of Appropriate Media and Cell Lines Recombinant $\mathrm{SeV}$ and hPIV3 have been reported to form plaques respectively in LLC-MK cells $^{10-12)}$ and HEp-2 cells. ${ }^{6}$ We compared our established method to the reported methods by using an overlay medium consisting of $2 \%$ BSA or $5 \% \mathrm{FBS}$ and an overlay staining medium consisting of $0.08 \mathrm{mg} / \mathrm{ml}$ neutral red and 5\% FBS (Fig. 2A). Both SeV and hPIV1 plaques were clearly visible by our method (Method

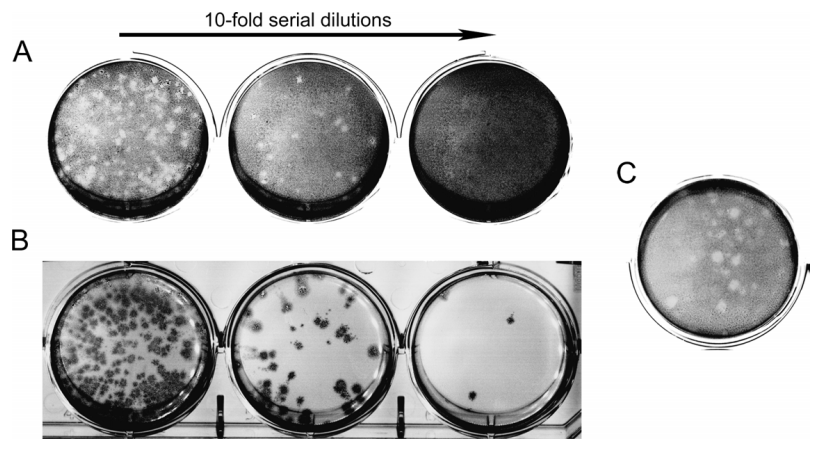

Fig. 1. Plaque Formation by hPIV1 Laboratory Strain C35 (A,B) and Clinical Isolate CL-5 (C) in LLC-MK 2 Cells

$(\mathrm{A}, \mathrm{C})$ Plaques were visualized by staining under agarose overlay containing neutral red. (B) Cell monolayers shown in panel A were fixed, and virus-infected cells were immunostained using rabbit anti-hPIV1 antibody and HRP-conjugated protein A.
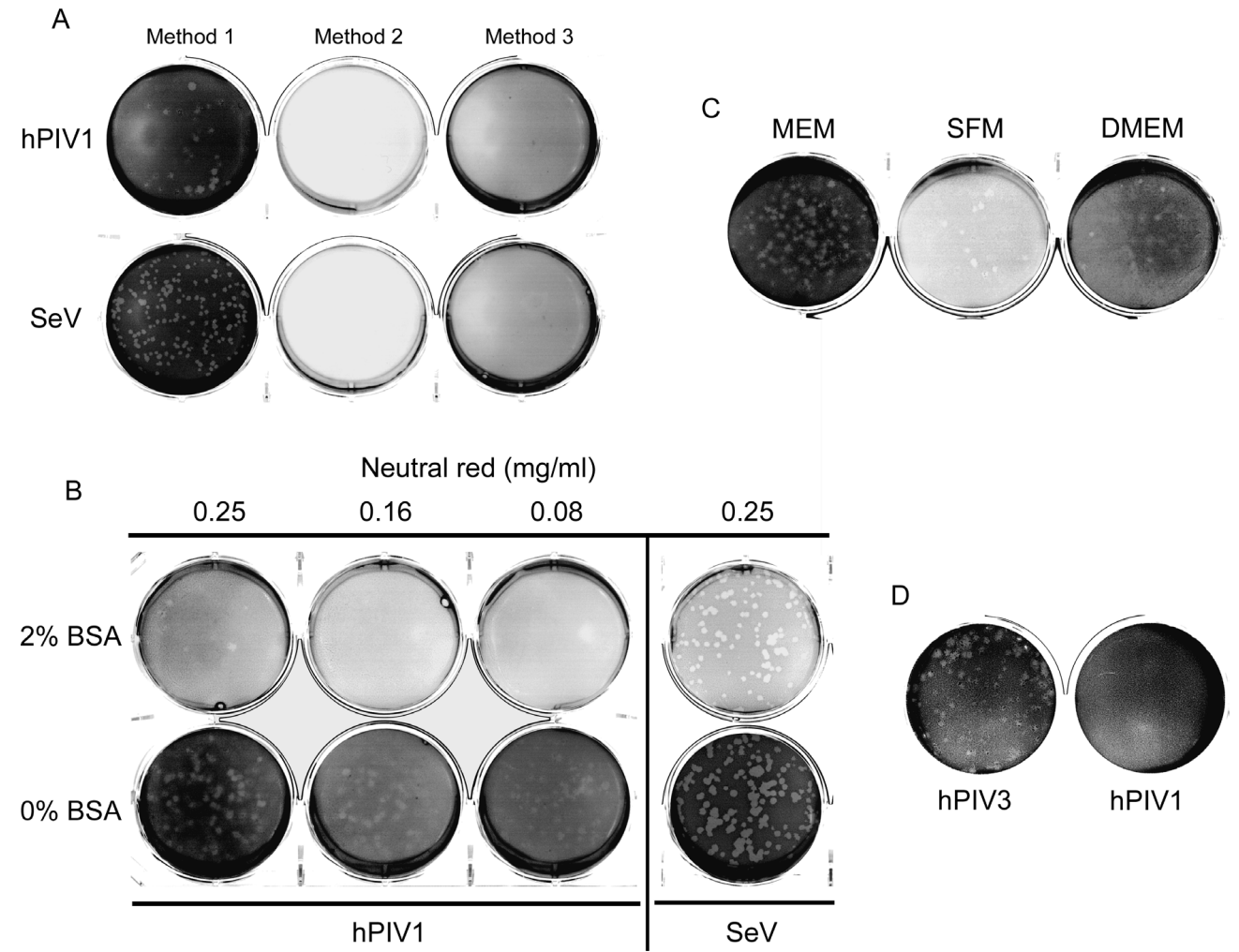

Fig. 2. Selection of Media and Cell Lines for Plaque Assay

(A) Comparison of the hPIV1 plaque formation assay and reported methods for recombinant SeV in LLC-MK 2 cells. Method 1 was performed in the same way as in Fig. $1 \mathrm{~A}$. In accordance with a previous report on recombinant $\mathrm{SeV}$, method 2 was performed using an overlay medium consisting of $1 \times \mathrm{MEM}, 0.8 \%$ agarose, $5 \mu \mathrm{g} / \mathrm{ml}$ acetylated trypsin and $2 \%$ BSA and an overlay staining medium consisting of $1 \times$ MEM, $0.8 \%$ agarose, $0.08 \mathrm{mg} / \mathrm{ml}$ neutral red and $5 \%$ FBS. Method 3 was performed using an overlay medium consisting of $1 \times$ MEM, $0.8 \%$ agarose, $5 \mu \mathrm{g} / \mathrm{ml}$ acetylated trypsin and 5\% FBS and an overlay staining medium of the same composition as that used in Method 2. (B) Comparison of the concentration of BSA and neutral red. hPIV1 and SeV plaque formation assay in LLC-MK 2 cells was performed using an overlay medium consisting of $1 \times$ MEM, $0.8 \%$ agarose, $3 \mu \mathrm{g} / \mathrm{ml}$ acetylated trypsion and without or with $2 \%$ BSA and an overlay staining medium consisting of $1 \times \mathrm{MEM}, 0.8 \%$ agarose and $0.25,0.16$ or $0.08 \mathrm{mg} / \mathrm{ml}$ neutral red. $(\mathrm{C})$

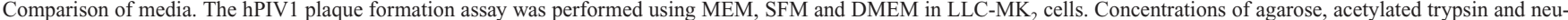
tral red and other conditions were the same as those in as Fig. 1A, method 1. (D) Comparison of cell lines. The hPIV1 and hPIV3 plaque formation assay was performed with DMEM in HEp-2 cells. Concentrations of agarose, acetylated trypsin and neutral red and other conditions were the same as those in Fig. 1A, Method 1. 


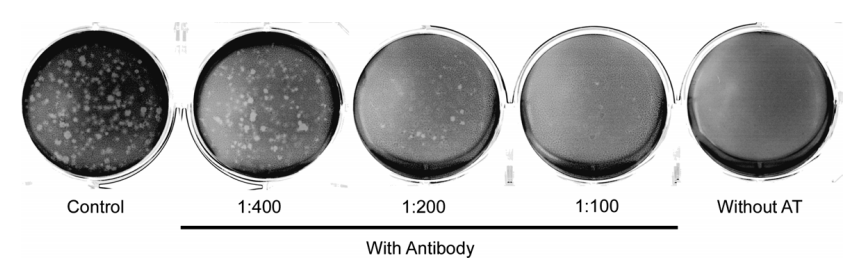

Fig. 3. Plaque Reduction Assay of hPIV1 Strain C35

The assay was performed as described in Materials and Methods in the presence of indicated dilutions of rabbit anti-hPIV1 antibodies, without antibodies (control) and without addition of acetylated trypsin (without AT).

1). On the other hand, in the reported methods using an overlay medium consisting 2\% BSA (Method 2) or 5\% FBS (Method 3) and an overlay staining medium containing $0.08 \mathrm{mg} / \mathrm{ml}$ neutral red and 5\% FBS, SeV plaques were barely visible (unable to be scanned) and hPIV1 plaques were not observed. To confirm whether concentrations of neutral red or BSA were effective for hPIV1 plaque formation and visualization, we checked these concentrations (Fig. 2B). The hPIV1 plaques were more clearly visualized with $0.25 \mathrm{mg} / \mathrm{ml}$ neutral red than with $0.08 \mathrm{mg} / \mathrm{ml}$ neutral red without BSA. With $2 \%$ BSA, plaques were barely observed with $0.25 \mathrm{mg} / \mathrm{ml}$ but they were unclear, and no hPIV1 plaques were observed with $0.08 \mathrm{mg} / \mathrm{ml}$. While BSA had little effect on $\mathrm{SeV}$ plaque formation, hPIV1 plaque formation, probably plaque visualization by neutral red staining, was strongly inhibited under the condition of $2 \%$ BSA. Neutral red was reported to bind to BSA with high affinity, ${ }^{22)}$ and shift in the emission peak to shorter wavelengths on binding to BSA. ${ }^{23)}$ BSA probably inhibited neutral red staining by preventing neutral red transport or $\mathrm{pH}$-dependent color change. Wild-type hPIV1 formed no plaques in the same conditions as those reported by Alymova et al. ${ }^{10,11)}$ and Watanabe et al. ${ }^{12)}$ for the assay of recombinant $\mathrm{SeV}$ possessing $\mathrm{HN}$ of hPIV1. Recombinant $\mathrm{SeV}$, which possesses the fusion protein of wild-type $\mathrm{SeV}$, may easily form plaques because of the strong fusion activity and propagation.

Tests using three media in the assay showed that MEM was a better medium for clear plaque formation of hPIV1 than was SFM or DMEM (Fig. 2C). The assay was also performed by using HEp-2 cells, which had been used for hPIV3 plaque assay in a previous study, ${ }^{6}$ instead of LLC$\mathrm{MK}_{2}$ cells. Although hPIV3 did show clear plaque formation as reported previously, no plaque of hPIV1 was observed in HEp-2 cells (Fig. 2D). Plaques of hPIV1 were also not observed in HeLa cells and Madin-Darby canine kidney cells (data not shown). Plaque assay conditions we tried in Fig. 2 were also summarized in Table 1.

Plaque Reduction Assay We examined inhibition of hPIV1 replication in the plaque reduction assay by addition of rabbit anti-hPIV1 antibody as an inhibitor to the overlay medium. Anti-hPIV1 antibody, which blocks attachment between the virus and the receptor on the host cell surface, significantly inhibited the number and size of plaques in a dose-dependent manner, compared to the overlay medium without the antibody (Fig. 3). No plaque was observed in the absence of acetylated trypsin, which activated the fusion glycoprotein on the virus membrane, as a control for complete inhibition. This result confirms that acetylated trypsin is essential for plaque formation of the virus (Fig. 3) and indi- cates that our plaque reduction assay will be useful for screening inhibitors of hPIV replication.

\section{DISCUSSION}

We established a plaque formation assay in LLC-MK ${ }_{2}$ cells for hPIV1 using an agarose overlay with neutral red, which easily visualized plaques. Normal live cells actively uptake neutral red and turn red. Although hPIV1-infected cells retain a normal shape when observed under an optical microscope because of low cytotoxicity, they actually show dysfunction of membrane transport processes such as endocytosis. The loss of neutral red uptake results in visualization of the virus-infected plaques as clear white circles. BSA inhibited visualization of hPIV1-induced plaques. BSA probably affected neutral red transportation or $\mathrm{pH}$-dependent color change, which is critical for hPIV1 plaque visualization. hPIV1 is a noncytopathic virus whereas hPIV3 and SeV readily produce extensive cytopathic effects (CPE). ${ }^{13,14)}$ Therefore $\mathrm{SeV}$ induces megascopic plaques without neutral red. In contrast, hPIV1 plaques were only observed by neutral red uptake.

Our established plaque assay of hPIV1 is applicable to virus titration, virus isolation and evaluation of virus inhibitors, since the plaques in the assay are visible and alive. It is important to visualize plaques of clinical hPIV1 strains. Since the limiting dilution method has been the only way to isolate hPIV1 from clinical specimens, only a few laboratory strains were available for the present study. The limiting dilution method is useful for isolation of the viruses. However, the absence of CPE in many of the cell lines used commonly makes it difficult to confirm hPIV1 growth. Our results confirmed applicability of the assay to a clinical hPIV1 strain. The assay will be suitable for isolation of hPIV1 from clinical specimens and for increasing virus strains available for basic research of hPIV1. In addition, the isolation would greatly advance phylogenic epidemiological analysis of clinical isolates and mutation analysis of variant viruses including inhibitor-resistant viruses.

The number of plaques is widely utilized as a general virological index of virus infection titer (often expressed as plaque-forming units). The plaque reduction assay is also widely utilized to evaluate efficiency of or resistance to antiviral reagents. ${ }^{15,16)}$ Our plaque assay will facilitate virus isolation, virus titration and evaluation of antiviral efficacy and will thus contribute greatly to the development of antiviral therapies, elucidation of infection mechanisms and epidemiology of hPIV1 prevalence.

Acknowledgements We thank Allen Portner (St. Jude Children's Research Hospital) for providing virus strains.

\section{REFERENCES}

1) Fry A. M., Curns A. T., Harbour K., Hutwagner L., Holman R. C., Anderson L. J., Clin. Infect. Dis., 43, 1016-1022 (2006).

2) Newman J. T., Riggs J. M., Surman S. R., McAuliffe J. M., Mulaikal T. A., Collins P. L., Murphy B. R., Skiadopoulos M. H., J. Virol., 78, 2017-2028 (2004)

3) Lucas J. R., Haas E. A., Masoumi H., Krous H. F., Pediatr. Dev. Pathol., 12, 165-168 (2009).

4) Henrickson K. J., Clin. Microbiol. Rev., 16, 242-264 (2003). 
5) Terlizzi M. E., Massimiliano B., Francesca S., Sinesi F., Rosangela V., Stefano G., Costa C., Rossana C., J. Virol. Methods, 160, 172-177 (2009).

6) McKimm-Breschkin J. L., J. Virol. Methods, 120, 113-117 (2004).

7) Shibuta H., Akami M., Matumoto M., Jpn. J. Microbiol., 15, 175183 (1971).

8) Sugita K., Maru M., Sato K., Jpn. J. Microbiol., 18, 262-264 (1974).

9) Scheid A., Choppin P. W., Virology, 69, 265-277 (1976).

10) Alymova I. V., Taylor G., Mishin V. P., Watanabe M., Murti K. G., Boyd K., Chand P., Babu Y. S., Portner A., J. Virol., 82, 8400-8410 (2008).

11) Alymova I. V., Watanabe M., Boyd K. L., Chand P., Babu Y. S., Portner A., Antivir. Ther. (London), 14, 891-898 (2009).

12) Watanabe M., Mishin V. P., Brown S. A., Russell C. J., Boyd K., Babu Y. S., Taylor G., Xiong X., Yan X., Portner A., Alymova I. V., Antimicrob. Agents Chemother, 53, 3942-3951 (2009).

13) Collins P. L., Chanock R. M., McIntosh K., "Fields Virology," 3rd ed., Vol. 1, ed. by Fields B. N., Knipe D. M., Howley P. M., Chanock R. M., Melnick J. L., Monath T. P., Roizman B., Straus S. E., LippincottRaven Publishers, Philadelphia, 1996, pp. 1205-1243.

14) Tao T., Durbin A. P., Whitehead S. S., Davoodi F., Collins P. L., Mur- phy B. R., J. Virol., 72, 2955-2961 (1998).

15) Giannecchini S., Campitelli L., Bandini G., Donatelli I., Azzi A., Virus Res., 129, 241-245 (2007)

16) Gubareva L. V., Bethell R., Hart G. J., Murti K. G., Penn C. R., Webster R. G., J. Virol., 70, 1818-1827 (1996).

17) Suzuki T., Portner A., Scroggs R. A., Uchikawa M., Koyama N., Matsuo K., Suzuki Y., Takimoto T., J. Virol., 75, 4604- 4613 (2001).

18) Henrickson K. J., Savatski L. L., J. Infect. Dis., 166, 995-1005 (1992).

19) Suzuki T., Ikeda K., Koyama N., Hosokawa C., Kogure T., Takahashi T., Hidari K. I., Miyamoto D., Tanaka K., Suzuki Y., Glycoconj. J., 18, $331-337$ (2001).

20) Conyers S. M., Kidwell D. A., Anal. Biochem., 192, 207-211 (1991).

21) Takahashi T., Murakami K., Nagakura M., Kishita H., Watanabe S., Honke K., Ogura K., Tai T., Kawasaki K., Miyamoto D., Hidari K. I., Guo C. T., Suzuki Y., Suzuki T., J. Virol., 82, 5940-5950 (2008).

22) Shang L., Jiang X., Dong S., J. Photochem. Photobiol. Chem., 184, 93-97 (2006).

23) Salomi B. S. B., Mitra C. K., Gorton L., Synth. Met., 155, 426- 429 (2005). 